Odessa State Environmental University, L’vovskaya str.15, Odessa-9, 65016, Ukraine E-mail: tkachtb@gmail.com

\title{
RELATIVISTIC CALCULATION OF THE HYPERFINE STRUCTURE PARAMETERS FOR COMPLEX ATOMS WITHIN MANY-BODY PERTURBATION THEORY
}

\begin{abstract}
The hyperfine structure parameters and electric quadrupole moment of the ${ }^{201} \mathrm{Hg}$ mercury isotope the Mn atom are estimated within the relativistic many-body perturbation theory formalism with a correct and effective taking into account the exchange-correlation, relativistic, nuclear and radiative corrections. Analysis of the data shows that an account of the interelectron correlation effects is crucial in the calculation of the hyperfine structure parameters. The fundamental reason of physically reasonable agreement between theory and experiment is connected with the correct taking into account the inter-electron correlation effects, nuclear (due to the finite size of a nucleus), relativistic and radiative corrections. The key difference between the results of the relativistic Hartree-Fock Dirac-Fock and manybody perturbation theory methods calculations is explained by using the different schemes of taking into account the inter-electron correlations as well as nuclear and radiative ones.
\end{abstract}

\section{Introduction}

The research on the hyperfine structure (HFS) characteristics of the heavy neutral and highly ionizedatomsis ofagreat fundamentalimportance in many fields of atomic physics (spectroscopy, spectral lines theory), astrophysics, plasma physics, laser physics and so on (see, for example, refs. [1-37]). The experiments on the definition of hyperfine splitting also enable to refine the deduction of nuclear magnetic moments of different isotopes and to check an accuracy of the various calculational models employed for the theoretical description of the nuclear effects. In recent years, due to significant progress in experimental studies, interest in studying the spectra of elements with empty d, f shells has sharply increased (see [1-10]). The multi-configuration relativistic Hartree-Fock (RHF), Dirac-Fock (DF), ulriconfiguration DF (MCDF) approaches (see, for example, refs. [19]) are the most reliable versions of calculation for multi-electron systems with a large nuclear charge. Usually, in these calculations the oneand two-body relativistic effects are taken into account practically precisely. It should be given the special attention to three very general and important computer systems for relativistic and QED calculations of atomic and molecular properties such as "GRASP", "Dirac"; "BERTHA", "QED", "Dirac" etc. (see refs. [19] and refs. there).

In this paper we present the calculational results for the HFS structure parameters for the Mn atom and electric quadrupole moment of the isotope ${ }^{201} \mathrm{Hg}$, using the optimized method of the relativistic many-body perturbation theory with the Dirac-Kohn-Sham zeroth approximation and a correct and effective taking into account the exchange-correlation, relativistic, nuclear and radiative corrections [9-30]. Analysis of the data shows that an account of the interelectron correlation effects is crucial in the calculation of the hyperfine structure parameters.

\section{Relativistic method to computing hyperfine structure parameters of atoms and ions}

Let us describe the key moments of the approach (more details can be found in refs. [19-30]). The electron wave functions (the PT zeroth basis) are found from solution of the relativistic Dirac equation with potential, which includes ab initio mean-field potential, electric, polarization potentials of a nucleus. The charge 
distribution in the Li-like ion is modelled within the Gauss model. The nuclear model used for the Cs isotope is the independent particle model with the Woods-Saxon and spin-orbit potentials (see refa. [20]). Let us consider in details more simple case of the Li-like ion. We set the charge distribution in the Li-like ion nucleus $\rho(r)$ by the Gaussian function:

$$
\rho(r \mid R)=\left(4 \gamma^{3 / 2} / \sqrt{\pi}\right) \exp \left(-\gamma r^{2}\right)
$$

where $\gamma=4 / \pi R^{2}$ and $R$ is the effective nucleus radius. The Coulomb potential for the spherically symmetric density $\rho(r)$ is:

$V_{\text {nucl }}(r \mid R)=-\left((1 / r) \int_{0}^{r} d r^{\prime} r^{\prime 2} \rho\left(r^{\prime} \mid R\right)+\int_{r}^{\infty} d r^{\prime} r^{\prime} \rho\left(r^{\prime} \mid R\right)(2)\right.$

Consider the DF type equations. Formally they fall into one-electron Dirac equations for the orbitals with the potential $V(r \mid R)$ which includes the electrical and the polarization potentials of the nucleus; the components of the Hartree potential (in the Coulomb units):

$$
V(r \mid i)=\frac{1}{Z} \int d \vec{r}^{\prime} \rho(r \mid i) /\left|\vec{r}-\vec{r}^{\prime}\right|
$$

Here $\rho(r \mid i)$ is the distribution of the electron density in the state $\mid i>, V_{e x}$ is the exchange interelectron interaction. The main exchange and correlation effects will be taken into account in the first two orders of the PT by the total interelectron interaction [21,22].

A procedure of taking into account the radiative QED corrections is in details given in the refs. [19,20].

Regarding the vacuum polarization effect let us note that this effect is usually taken into consideration in the first PT theory order by means of the Uehling-Serber potential. This potential is usually written as follows:

$$
U(r)=-\frac{2 \alpha}{3 \pi r} \int_{1}^{\infty} d \exp (-2 t / \alpha Z)\left(1+1 / 2 t^{2}\right) \frac{\sqrt{t^{2}-1}}{t^{2}} \equiv
$$

$$
=-\frac{2 \alpha}{3 \pi r} C(g),
$$

where $g=r /(\alpha Z)$. In our calculation we use more exact approach [20]. The Uehling potential, determined as a quadrature (5), may be approximated with high precision by a simple analytical function. The use of new approximation of the Uehling potential permits one to decrease the calculation errors for this term down to $0.5-1 \%$.

A method for calculation of the self-energy part of the Lamb shift is based on the methods [19-24]. The radiative shift and the relativistic part of energy in an atomic system are, in principle, defined by one and the same physical field. One could suppose that there exists some universal function that connects the self-energy correction and the relativistic energy.

Its form and properties are in details analyzed in Refs.[19-24,30-35]. Unlike usual purely electronic atoms, the Lamb shift self-energy part in the case of a pionic atom is not significant and much inferior to the main vacuum-polarization effect.

The energies of electric quadruple and magnetic dipole interactions are defined by a standard way with the hyperfine structure constants, usually expressed through the standard radial integrals:

$$
\begin{gathered}
A=\left\{\left[(4,32587) 10^{-4} Z^{2} \chi g_{p}\right] /\left(4 \chi^{2}-1\right)\right\}(R A)_{-2}, \\
B=\left\{7.287810^{-7} Z^{3} Q /\left[\left(4 \chi^{2}-1\right) I(I-1)\right\}(R A)_{-3},\right.
\end{gathered}
$$

Here $g_{I}$ is the Lande factor, $Q$ is a quadruple momentum of nucleus (in Barn); $(R A)_{-2},(R A)$. ${ }_{3}$ are the radial integrals usually defined as follows:

$$
\begin{aligned}
& (R A)_{-2}=\int_{0}^{\infty} d r r^{2} F(r) G(r) U\left(1 / r^{2}, R\right) \\
& (R A)_{-3}=\int_{0}^{\infty} d r r^{2}\left[F^{2}(r)+G^{2}(r) U\left(1 / r^{2}, R\right) .\right.
\end{aligned}
$$

The radial parts $F$ and $G$ of the Dirac function two components for electron, which moves in 
the potential $V(r, R)+U(r, R)$, are determined by solution of the Dirac equations.

The key elements of the numerical approach to computing the corresponding matrix elements are presented in [19-36]. All calculations are performed on the basis of the numeral code Superatom-ISAN (version 93).

\section{Results and Conclusions}

In this subsection we present experimental data and the results of the calculation of the HFS parameters for some complex atoms. It should be noted that the Mn element has one stable isotope with a mass number of 55 , a nuclear spin of $5 / 2$, a magnetic dipole moment of $3.46871668 \boldsymbol{m}_{\text {я }}$ and an electric quadrupole moment of $\mathrm{Q}=0.33$ (1) barn. Basic electronic configuration: $3 \mathrm{~d}^{5} 4 \mathrm{~s}^{2}$ $\left({ }^{6} \mathrm{~S}_{5 / 2}\right)$.

Given the complexity of the spectrum, theoretical study of the HFS should be based on a full multi-electron calculation. An useful review and detailed analysis of the studies of the HFS of the Mn atom was given, for example, in [6].

In table 1 we present the available experimental $\left(\mathrm{A}_{\exp }, \mathrm{B}_{\exp }\right)$ and theoretical (our calculation) values of the energy levels and the HFS parameters for the Mn configuration $3 \mathrm{~d}^{5} 4 \mathrm{~s}^{2}, 3 \mathrm{~d} 64 \mathrm{~s}$. The reasonable agreement between theoretical and measured data can be reached by way of using the optimized wave functions basises and complete, correct accounting for the exchange-correlation corrections.

Further we present the results of calculating the HFS constants and the electric quadrupole moment for the ${ }^{201} \mathrm{Hg}$ isotope. The mercury atom has an external valent configuration $6 s^{2}$ and can be considered within the many-body paerturbation theory as the two-quasipartial system. Mercury has one stable isotope ${ }^{201} \mathrm{Hg}$ (I $=3 / 2$ ) with a relative prevalence of $13.2 \%$.

The ${ }^{199} \mathrm{Hg}$ isotope with a relative distribution of $16.9 \%$ has two quadrupole excited states with energies of 158 and $208 \mathrm{keV}$. The values of quadrupole moment for a few radioactive isotopes with masses from 185 to 203 are presented by the group Ulm and others (see, for example, $[4,5])$.
Table 1.

Experimental ( $\left.\mathrm{A}_{\text {exp }}, \mathrm{E}_{\text {exp }}\right)$ and theoretical (our calculation) values of the energy levels $\left(\mathrm{cm}^{-1}\right)$ and HFS constants $(\mathrm{MHz})$ for the Mn configuration $3 d^{5} 4 s^{2}$

\begin{tabular}{|c|c|c|c|}
\hline Level & Term & $E_{\text {exp }}$ & $E_{t h}$ \\
\hline $3 d^{5} 4 s^{2}$ & $\mathrm{a}^{6} \mathrm{~S}_{5 / 2}$ & 0.0 & 0.0 \\
\hline $3 d^{6} 4 s$ & $a^{6} D_{9 / 2}$ & 17052.29 & 17001.38 \\
\hline $3 d^{6} 4 s$ & $a^{6} D_{7 / 2}$ & 17282.00 & 17209.34 \\
\hline $3 d^{6} 4 s$ & $\mathrm{a}^{6} \mathrm{D}_{5 / 2}$ & 17451.52 & 17394.91 \\
\hline $3 d^{6} 4 s$ & $\mathrm{a}^{6} \mathrm{D}_{3 / 2}$ & - & 17500.12 \\
\hline $3 d^{6} 4 s$ & $a^{6} D_{1 / 2}$ & - & 17565.24 \\
\hline $3 d^{5} 4 s^{2}$ & $a^{4} G_{11 / 2}$ & 25265.74 & 25201.43 \\
\hline $3 d^{5} 4 s^{2}$ & $\mathrm{a}^{4} \mathrm{G}_{5 / 2}$ & 25281.04 & 25219.45 \\
\hline $3 d^{5} 4 s^{2}$ & $a^{4} G_{9 / 2}$ & 25285.43 & 25221.36 \\
\hline $3 d^{5} 4 s^{2}$ & $a^{4} G_{7 / 2}$ & 25287.74 & 25224.16 \\
\hline $3 d^{5} 4 s^{2}$ & $\mathrm{~b}^{4} \mathrm{D}_{5 / 2}$ & 30419.61 & 30382.46 \\
\hline $3 d^{5} 4 s^{2}$ & $\mathrm{~b}^{4} \mathrm{D}_{3 / 2}$ & - & 30374.97 \\
\hline Level & Term & $A_{\exp }$ & $A_{\text {th }}$ \\
\hline $3 d^{5} 4 s^{2}$ & $\mathrm{a}^{6} \mathrm{~S}_{5 / 2}$ & -72.4 & -73 \\
\hline $3 d^{6} 4 s$ & $a^{6} D_{9 / 2}$ & $503(8)$ & 504 \\
\hline $3 d^{6} 4 s$ & $a^{6} D_{7 / 2}$ & $457(3)$ & 457 \\
\hline $3 d^{6} 4 s$ & $a^{6} D_{5 / 2}$ & $434(4)$ & 434 \\
\hline $3 d^{6} 4 s$ & $a^{6} D_{3 / 2}$ & $467(6)$ & 466 \\
\hline $3 d^{6} 4 s$ & $a^{6} D_{1 / 2}$ & $892(16)$ & 891 \\
\hline $3 d^{5} 4 s^{2}$ & $\mathrm{a}^{4} \mathrm{G}_{11 / 2}$ & 405.3(9) & 405.4 \\
\hline $3 d^{5} 4 s^{2}$ & $a^{4} G_{5 / 2}$ & 596.2(9) & 596.0 \\
\hline $3 d^{5} 4 s^{2}$ & $a^{4} G_{9 / 2}$ & $395.2(3)$ & 395.1 \\
\hline $3 d^{5} 4 s^{2}$ & $\mathrm{a}^{4} \mathrm{G}_{7 / 2}$ & 437,1 & 437.4 \\
\hline $3 d^{5} 4 s^{2}$ & $b^{4} D_{5 / 2}$ & $288(5)$ & 290 \\
\hline $3 d^{5} 4 s^{2}$ & $b^{4} D_{3 / 2}$ & 456 & 453 \\
\hline Level & Term & $\mathrm{B}_{\exp }$ & $\mathrm{B}_{\mathrm{th}}$ \\
\hline $3 d^{5} 4 s^{2}$ & $a^{6} S_{5 / 2}$ & 0.019 & 0.016 \\
\hline $3 d^{5} 4 s^{2}$ & $\mathrm{~b}^{4} \mathrm{D}_{5 / 2}$ & $130(5)$ & 129 \\
\hline $3 d^{5} 4 s^{2}$ & $\mathrm{~b}^{4} \mathrm{D}_{3 / 2}$ & - & -36 \\
\hline
\end{tabular}


A reasonable compilation of the values of quadrupole moments for isotopes in the mass range 185-206 is presented in the wellknown Raghavan table. Currently available experimental values of the quadrupole moment Q $(201 \mathrm{Hg})$ are given in table 2. The muon "muonic 3d" value of 386 (49) mb was used in the recent final report "year-2001" on the nuclear quadrupole moments [6].

Table 2.

The values of the electric quadrupole moment $\mathrm{Q}(\mathrm{mb})$ for isotope of ${ }^{201} \mathrm{Hg}$

\begin{tabular}{|c|c|c|c|}
\hline$Q(\mathrm{mb})$ & Method & Ref. & Year \\
\hline 383 & Atomic & This work & 2018 \\
\hline 381 & Atomic & Khetselius & 2006 \\
\hline $387(6)$ & Atomic & Pyykko et al & 2005 \\
\hline $347(43)$ & Nuclear & Fornal et al & 2001 \\
\hline $385(40)$ & Atomic $^{\mathrm{a}}$ & Ulm et al & 1988 \\
\hline $485(68)$ & Muonic $^{\mathrm{b}}$ & Gunther et & 1983 \\
\hline 386 (49) & Muonic & al & 1979 \\
\hline $267(37)$ & $3 \mathrm{~d}^{\mathrm{c}}$ & Hahn et al & 1979 \\
\hline $390(20)$ & $\begin{array}{c}\text { Muonic } \\
2 \mathrm{p}^{\mathrm{c}}\end{array}$ & $\begin{array}{l}\text { Hahn et al } \\
\text { Edelstein- }\end{array}$ & 1975 \\
\hline $455(40)$ & Solid $^{d}$ & $\begin{array}{c}\text { Pound } \\
\text { McDermott- }\end{array}$ & 1960 \\
\hline 420 & Atomic & Lichten & 1959 \\
\hline $500(50)$ & ${ }^{3} \mathrm{P}_{2}$ & $\begin{array}{c}\text { Murakawa } \\
\text { Blaise- }\end{array}$ & 1957 \\
\hline 600 & Atomic & Chantrel & 1954 \\
\hline \multirow[t]{3}{*}{500} & Atomic & $\begin{array}{c}\text { Dehmelt et } \\
\text { al }\end{array}$ & 1935 \\
\hline & Solid $^{\mathrm{e}}$ & $\begin{array}{l}\text { Schuler- } \\
\text { Schmidt }\end{array}$ & \\
\hline & Atomic $^{e}$ & & \\
\hline
\end{tabular}

Note: a- standard Raghavan value; the value of ${ }^{199} \mathrm{Hg}(\mathrm{I}=5 / 2)$ is consistent with the ratio 201/199; $\mathrm{c}$ - direct muon experiment for ${ }^{201} \mathrm{Hg}$; d- solid state $\mathrm{HgCl}_{2}$ plus compiled value ${ }^{199} \mathrm{Hg}$;

In table 3 we list the experimental and calculated values of the nuclear electric quadrupole moment $\mathrm{Q}(\mathrm{mb})$ for ${ }^{201} \mathrm{Hg}$ and the HFS constants $(\mathrm{MHz})$ for the ${ }^{3} \mathbf{P}_{1}$ state of the ${ }^{201} \mathrm{Hg}$ neutral mercury. The calculations were performed within the uncorrelated DF method, multi-configuration DF (MCDF) approximation with accounting for the Breit-QED corrections [6], the N-QED theory with an accounting for the Breit-QED corrections [20], and the present method (RMBPT) with the Gaussian model for a nuclear density distribution). The value of $\mathrm{Q}$ obtained by us is in the best agreement with the data obtained by the group Ulm. Comparison of our calculational results and data by the DF method (single-configuration and multiconfiguration approximations taking into account the Breit and QED corrections) shows that our values of the constant $A$ are in

Table 3.

Experimental and calculated values of the nuclear electric quadrupole moment $Q(\mathrm{mb})$ for ${ }^{201} \mathrm{Hg}$ and the values of the HFS constants (MHz) for the ${ }^{3} \mathbf{P}_{1}$ state of a neutral mercury atom ${ }^{201} \mathrm{Hg}$ states (see text)

\begin{tabular}{|l|c|}
\hline Method & $Q(\mathrm{mb})$ \\
\hline DF & 478.13 \\
\hline MCDF (+Breit_QED) & 386.626 \\
\hline N-QED & 380.518 \\
\hline This work (e-Corr) & -90.824 \\
\hline This work (Breit+QED) & -2.420 \\
\hline This work (Total) & 380.518 \\
\hline Exp. & Look Table 2 \\
\hline Method & A (MHz) \\
\hline DF & -4368.266 \\
\hline MCDF (+Breit_QED) & -5470.810 \\
\hline N-QED & -5460.324 \\
\hline This work (e-Corr) & -1162 \\
\hline This work (Breit+QED) & -20.868 \\
\hline This work (Total) & $-5460, .324$ \\
\hline Exp. & $-5454.569(0.003)$ \\
\hline Method & B (MHz) \\
\hline DF & --- \\
\hline MCDF (+Breit_QED) & --- \\
\hline
\end{tabular}




\begin{tabular}{|l|c|}
\hline N-QED & -286.512 \\
\hline This work (e-Corr) & -60.974 \\
\hline This work (Breit+QED) & -1.099 \\
\hline This work (Total) & -286.512 \\
\hline Exp. & $-280.107(0,005)$ \\
\hline
\end{tabular}

reasonable agreement with the experiment. The analysis shows that the contribution due to the electron - electron correlations $t$ o the values of the HFS constants is $\sim 100-500 \mathrm{MHz}$ for various states. This circumstance explains the low degree of consistency in accuracy of the data provided, obtained in the framework of different versions of the DF method. The key difference between the results of the calculation in the framework of our approach and the MCDF is due to different methods of taking into account the electron-electron correlations.

The contributions of higher-order QED TV corrections and corrections for the finite core size can reach 1-2 tens of $\mathrm{MHz}$, and it seems obviously important to consider them more correctly. In addition, it is necessary to take direct account of nuclear polarization contributions, which can be done within the framework of solving the corresponding nuclear problem, for example, using the shell model with Woods-Saxon and spin-orbit potentials. Such an approach is outlined in Refs [20,33]. These topics require the separated accurate treatment.

\section{References}

1. Grant I. Relativistic Quantum Theory of Atoms and Molecules. Oxford, 2007.

2. Glushkov, A; Khetselius, O; Svinarenko, A; Buyadzhi, V. Spectroscopy of autoionization states of heavy atoms and multiply charged ions. Odessa: 2015.

3. Khetselius, O.Yu. Hyperfine structure of atomic spectra. Astroprint: 2008.

4. Pyykko, P. Year2008 nuclear quadrupole moments. Mol. Phys. 2008, 106, 16.

5. Bieron J., Pyykkő P., Jonsson P. Nuclear quadrupole moment of ${ }^{201} \mathrm{Hg}$. Phys.Rev. A. 2005, 71, 012502.

6. Basar Gu., Basar Go., Acar G., Ozturk I.K.,
Kroger S. Hyperfine structure investigations of MnI: Experimental and theoretical studies of the hyperfine structure in the even configurations. Phys.Scr. 2003, 67, 476-484.

7. Gubanova E., Glushkov A., Khetselius O., Bunyakova Yu., Buyadzhi V., Pavlenko E. New methods in analysis and project management of environmental activity: Electronic and radioactive waste. FOP: Kharkiv, 2017.

8. Florko, T.A.; Tkach, T.B.; Ambrosov, S.V.; Svinarenko, A.A. Collisional shift of the heavy atoms hyperfine lines in an atmosphere of the inert gas. J. Phys.: Conf. Ser. 2012, 397, 012037.

9. Khetselius, O.Yu., Lopatkin Yu.M., Dubrovskaya, Yu.V, Svinarenko A.A. Sensing hyperfine-structure, electroweak interaction and parity non-conservation effect in heavy atoms and nuclei: New nuclear-QED approach. Sensor Electr. and Microsyst. Techn. 2010, 7(2), 11-19

10. Glushkov, A.V. Relativistic Quantum theory. Quantum mechanics of atomic systems. Astroprint: Odessa, 2008.

11. Khetselius, O.Yu. Atomic parity non-conservation effect in heavy atoms and observing $\mathrm{P}$ and $\mathrm{PT}$ violation using NMR shift in a laser beam: To precise theory. J. Phys.: Conf. Ser. 2009, 194, 022009

12. Khetselius, O.Yu. Hyperfine structure of radium. Photoelectronics. 2005, 14, 83.

13. Khetselius, O.. Relativistic perturbation theory calculation of the hyperfine structure parameters for some heavy-element isotopes. Int. Journ. Quant. Chem. 2009, 109, 3330-3335.

14. Khetselius, O.Yu. Relativistic calculation of the hyperfine structure parameters for heavy elements and laser detection of the heavy isotopes. Phys.Scripta. 2009, 135, 014023.

15. Khetselius, O.Yu. Relativistic Hyperfine Structure Spectral Lines and Atomic Parity Non-conservation Effect in Heavy Atomic Systems within QED Theory. AIP Conf. Proc. 2010, 1290(1), 29-33.

16. Khetselius O.Yu.; Gurnitskaya, E.P. Sensing the hyperfine structure and nuclear quadrupole moment for radium. Sensor Electr. and 
Microsyst. Techn. 2006, 2, 25-29.

17. Khetselius, O.Yu.; Gurnitskaya, E.P. Sensing the electric and magnetic moments of a nucleus in the N-like ion of Bi. Sensor Electr. and Microsyst. Techn. 2006, 3, 35-39.

18. Khetselius, O.Yu. Relativistic calculating the spectral lines hyperfine structure parameters for heavy ions. AIP Conf. Proc. 2008, 1058, 363-365.

19. Glushkov, A.V. Relativistic and correlation effects in spectra of atomic systems. Astroprint: Odessa, 2006.

20. Khetselius, O.Yu. Quantum structure of electroweak interaction in heavy finite Fermi-systems. Astroprint: Odessa, 2011.

21. Svinarenko, A.A. Study of spectra for lanthanides atoms with relativistic many- body perturbation theory: Rydberg resonances. $J$. Phys.: Conf. Ser. 2014, 548, 012039.

22. Svinarenko, A. A., Glushkov, A. V., Khetselius, O.Yu., Ternovsky,V.B., Dubrovskaya, Yu., Kuznetsova, A., Buyadzhi, V. Theoretical spectroscopy of rare-earth elements: spectra and autoionization resonances. Rare Earth Element, Ed. J. Orjuela (InTech) 2017, pp 83-104.

23. Khetselius, O.Yu. Optimized relativistic many-body perturbation theory calculation of wavelengths and oscillator strengths for Li-like multicharged ions. Adv. Quant. Chem. 2019, 78, 223-251.

24. Khetselius, O. Optimized perturbation theory for calculating the hyperfine line shift and broadening of heavy atoms in a buffer gas. In Frontiers in Quantum Methods and Applications in Chemistry and Physics, Springer: Cham, 2015; Vol. 29, pp. 55-76

25. Glushkov, A.V., Khetselius, O.Yu., Svinarenko A.A., Buyadzhi, V.V., Ternovsky, V.B, Kuznetsova, A., Bashkarev, P Relativistic perturbation theory formalism to computing spectra and radiation characteristics: application to heavy element. Recent Studies in Perturbation Theory, ed. D. Uzunov (InTech) 2017, 131-150.

26. Glushkov A., Lovett L., Khetselius O., Gurnitskaya E., Dubrovskaya Y., Loboda A. Generalized multiconfiguration model of decay of multipole giant resonances applied to analysis of reaction ( $\mu-n)$ on the nucleus ${ }^{40}$ Ca. Int. J. Mod. Phys. A. 2009, 24(2-3), 611-615

27. Dubrovskaya, Yu., Khetselius, O.Yu., Vitavetskaya, L., Ternovsky, V., Serga, I. Quantum chemistry and spectroscopy of pionic atomic systems with accounting for relativistic, radiative, and strong interaction effects. Adv. in Quantum Chem. 2019, Vol.78, pp 193-222.

28. Bystryantseva A., Khetselius O.Yu., Dubrovskaya Yu., Vitavetskaya L.A., Berestenko A.G. Relativistic theory of spectra of heavy pionic atomic systems with account of strong pion-nuclear interaction effects: ${ }^{93} \mathrm{Nb},{ }^{173} \mathrm{Yb},{ }^{181} \mathrm{Ta},{ }^{197} \mathrm{Au}$. Photoelectronics. 2016, 25, 56-61.

29. Khetselius, O., Glushkov, A., Gurskaya M., Kuznetsova, A., Dubrovskaya, Yu., Serga I., Vitavetskaya, L. Computational modelling parity nonconservation and electroweak interaction effects in heavy atomic systems within the nuclear-relativistic many-body perturbation theory. J. Phys.: Conf. Ser. 2017, 905(1), 012029.

30. Khetselius, O.Yu., Glushkov, A.V., Dubrovskaya, Yu.V., Chernyakova, Yu., Ignatenko, A.V., Serga, I., Vitavetskaya, L. Relativistic quantum chemistry and spectroscopy of exotic atomic systems with accounting for strong interaction effects. In: Concepts, Methods and Applications of Quantum Systems in Chemistry and Physics. Springer, Cham, 2018, 31, 71-91.

31. Svinarenko A., Khetselius O., Buyadzhi V., Florko T., Zaichko P., Ponomarenko E. Spectroscopy of Rydberg atoms in a Blackbody radiation field: Relativistic theory of excitation and ionization. J. Phys.: Conf. Ser. 2014, 548, 012048.

32. Svinarenko, A.; Ignatenko, A.; Ternovsky, V.B.; Nikola, L.; Seredenko, S.S.; Tkach, T.B. Advanced relativistic model potential approach to calculation of radiation transition parameters in spectra of multicharged ions. J. Phys.: Conf. Ser. 2014, 548, 012047.

33. Glushkov A Spectroscopy of cooperative muon-gamma-nuclear processes: Energy and spectral parameters J. Phys.: Conf. Ser. 
2012, 397, 012011.

34. Glushkov, A.V. Spectroscopy of atom and nucleus in a strong laser field: Stark effect and multiphoton resonances. J. Phys.: Conf. Ser. 2014, 548, 012020

35. Glushkov A.V.; Ivanov, L.N. DC strongfield Stark effect: consistent quantum-me- chanical approach. J. Phys. B: At. Mol. Opt. Phys. 1993, 26, L379-386.

36. Glushkov A.V., Khetselius O.Yu., Svinarenko A.A., Buyadzhi V.V., Methods of computational mathematics and mathematical physics. P.1. TES: Odessa, 2015.

PACS 31.30.Gs

О. О. Антошкіна, М. П. Макушкіна, О. Ю. Хецеліус, Т. Б. Ткач

\title{
РЕЛЯТИВІСТСЫКИЙ РОЗРАХУНОК ПАРАМЕТРІВ НАДТОНКОЇ СТРУКТУРИ СКЛАДНИХ АТОМІВ В РАМКАХ БАГАТОЧАСТИНКОВОЇ ТЕОРІЇ ЗБУРЕНЬ
}

\begin{abstract}
Резюме. Параметри надтонкою структури і електричний квадрупольний момент ізотопу ртуті ${ }^{201} \mathrm{Hg}$ і атома Мn розраховані на основі релятивістської багаточастинкової теорії збурень з ефективним акуратним урахуванням обмінно-кореляційних, релятивістських, ядерних і радіаційних поправок. Аналіз даних показує, що урахування ефектів міжелектронної кореляції має критичне значення при обчисленні параметрів надтонкої структури. Фізично розумне узгодження теорії і прецизійного експерименту може бути забезпечено завдяки повному послідовному обліку міжелектронних кореляційних ефектів, ядерних, релятивістських та радіаційних поправок. Ключова відмінність між результатами розрахунків в наближеннях Дірака-Фока, різних версіях формалізму теорії збурень в основному пов'язано 3 використанням різних схем обліку міжелектронних кореляцій, а також врахування ядерних і радіаційних поправок.

Ключові слова: Надтонка структура, важкий атом, релятивістська теорія збурень, кореляційні, ядерні, радіаційні поправки
\end{abstract}

PACS 31.30.Gs

O. A. Antoshkina, M. P. Makushkina, O. Yu. Khetselius, T. B. Tkach

\section{RELATIVISTIC CALCULATION OF THE HYPERFINE STRUCTURE PARAMETERS FOR COMPLEX ATOMS WITHIN MANY-BODY PERTURBATION THEORY}

Summary. The hyperfine structure parameters and electric quadrupole moment of the ${ }^{201} \mathrm{Hg}$ mercury isotope the $\mathrm{Mn}$ atom are estimated within the relativistic many-body perturbation theory formalism with a correct and effective taking into account the exchange-correlation, relativistic, nuclear and radiative corrections. Analysis of the data shows that an account of the interelectron correlation effects is crucial in the calculation of the hyperfine structure parameters. The fundamental reason of physically reasonable agreement between theory and experiment is connected with the correct taking into account the inter-electron correlation effects, nuclear (due to the finite size of a nucleus), relativistic and radiative corrections. The key difference between the results of the 
relativistic Hartree-Fock Dirac-Fock and many-body perturbation theory methods calculations is explained by using the different schemes of taking into account the inter-electron correlations as well as nuclear and radiative ones.

Keywords: Hyperfine structure, Heavy atoms, Relativistic perturbation theory, correlation, nuclear, radiative corrections

PACS 31.30.Gs

О. А. Антошкина, М. П. Макушкина, О. Ю. Хецелиус, Т. Б. Ткач

\section{РЕЛЯТИВИСТСКИЙ РАСЧЕТ ПАРАМЕТРОВ СВЕРХТОНКОЙ СТРУКТУРЫ СЛОЖНЫХ АТОМОВ В РАМКАХ МНОГОЧАСТИЧНОЙ ТЕОРИИ ВОЗМУЩЕНИЙ}

Резюме. Параметры сверхтонкой структуры и электрический квадрупольный момент изотопа ртути ${ }^{201} \mathrm{Hg}$ и атома $\mathrm{Mn}$ рассчитаны на основе релятивистской многочастичной теории возмущений с эффективным аккуратным учетом обменно-корреляционных, релятивистских, ядерных и радиационных поправок. Анализ данных показывает, что учет эффектов межэлектронной корреляции имеет критическое значение при вычислении параметров сверхтонкой структуры. Физически разумное согласие теории и прецизионного эксперимента может быть обеспечено благодаря полному последовательному учету межэлектронных корреляционных эффектов, ядерных, релятивистских и радиационных поправок. Ключевое различие между результатами расчетов в приближениях Дирака-Фока, различных версиях формализма теории возмущений в основном связано с использованием различных схем учета межэлектронных корреляций, а также учета ядерных и радиационных поправок.

Ключевые слова: Сверхтонкая структура, тяжелый атом, релятивистская теория возмущений, корреляционные, ядерные, радиационные поправки 
PACS 31.15.-p

\title{
V. V. Buyadzhi
}

Odessa State Environmental University, 15, Lvovskaya str., Odessa-16, 65016, Ukraine

E-mail: buyadzhivv@gmail.com

\section{ELECTRON-COLLISIONAL SPECTROSCOPY OF ATOMS AND IONS: ADVANCED ENERGY APPROACH}

\begin{abstract}
An advanced relativistic energy approach combined with a scattering theory is used to calculate the electroncollision excitation cross-sections, collision strengths for a number of multicharged ions. The relativistic many-body perturbation theory is used alongside the gauge-invariant scheme to generate an optimal Dirac-Kohn-Sham- DebyeHückel one-electron representation. The results of relativistic calculation (taking into account the exchange and correlation corrections) of the electron collision cross-sections (strengths) of excitation of the transition between the fine-structure levels $\left(2 \mathrm{P}_{3 / 2}-2 \mathrm{P}_{1 / 2}\right)$ of the ground state of F-like ions with $\mathrm{Z}=19-26$ and of the $\left[2 \mathrm{~s}^{2}{ }^{1} \mathrm{~S}-\left(2 \mathrm{~s} 2 \mathrm{p}{ }^{1} \mathrm{P}\right)\right]$ transition in the $\mathrm{B}-$ like $\mathrm{O}^{4+}$ are presented and analysed.
\end{abstract}

\section{Introduction}

Electron-collisional spectroscopy of atoms and multicharged ions is one of the most fast developing branches of modern atomic spectroscopy. The properties of laboratory and astrophysical plasmas have drawn considerable attention over the last decades [1-15]. It is known that multicharged ions play an important role in the diagnostics of a wide variety of plasmas. Similar interest is also stimulated by importance of this information for correct determination of the characteristics for plasma in thermonuclear (tokamak) reactors, searching new mediums for $\mathrm{X}$-ray range lasers.

In the case of solving collision problems involving multi-electron atomic systems, as well as low-energy processes, etc., the structure of atomic systems should be described on the basis of rigorous methods of quantum theory. As a rule, the Hartree-Fock (HF) or HartreeFock-Slater (HFS) models implemented in the tight-binding approximation were used to describe the wave functions of the bound states of atoms and ions. Another direction is the models of the central potential (model potential, pseudopotential) implemented in the distorted wave approximation (DWA). It should be mentioned the currently widespread and widely used Rmatrix method and its various promising modifications, as well as a generalization of the wellknown Dirac-Fock method to the case of taking into account multipolarity in the corresponding operators (see, e.g. , [1-7]). It should be noted that, depending on the perturbation theory (PT) basis used, different versions of the R-matrix method received the corresponding names. For example, in specific calculations such versions as R-MATR-CI3-5R and R-MATR-41 R-matrix method were used using respectively wave functions in the multiconfiguration approximation, in particular, 5- and 41- configuration wave functions. As numerous applications of the R-matrix method have shown, it has certain advantages in terms of accuracy and consistency over such popular approaches as the first-order PT method, as well as the distorted wave approximation taking into account configuration interaction ( CIDWBA); --- approximation of distorted waves using the HF basis (HF-DWBA), finally, the relativistic approximation of distorted waves with a 1-configuration and multi-configuration wave function of the ground state (SCGS-RDWA, MCGS-RDWA, etc.). Improved models have also appeared in theories of the coupled-channel (VC) type VCDWA (Variational Continuum Distorted Wave), for example, a modification of the Vraun-Scroters type and others (see [1-5]). Various cluster methods have also been widely used (see in more details [1-3,14,15]).

In this paper, we present and use an advanced relativistic energy approach to calculate the electron-ion collision strengths, effective 